\title{
Influence of Bioactive Materials Used on the Dentin Surface Whitened with Carbamide Peroxide 16\%
}

\author{
Helena Burlamaqui Pinheiro ${ }^{\text {a }}$ Bruno Lopes ${ }^{\text {a }}$ Eliza Burlamaqui Klautau ${ }^{\text {, }}$ \\ Jomara Cardoso ${ }^{c}$, Bruna Rozzetti Silva ${ }^{\text {a }}$, Paulo Eduardo Capel Cardoso ${ }^{\text {a }}$ * \\ ${ }^{a}$ Department of Biomaterials, Dental School, University of São Paulo - USP, \\ Av. Prof. Lineu Prestes, 2227, CEP 05508-000 Cidade Universitária, São Paulo, SP, Brazil \\ ${ }^{\mathrm{b}}$ Department of Biomaterials, Dental School, Federal University of Pará, \\ Av. 09 de Janeiro, 1613/701, CEP 66063-260 São Braz, Belém, PA, Brazil \\ 'Instituto de Ensino e Pesquisa - Insper, \\ Av. Prof. Lineu Prestes, 2227, CEP 05508-000 Cidade Universitária, São Paulo, SP, Brazil
}

Received: April 13, 2010; Revised: May 21, 2010

\begin{abstract}
This study investigated the influence of bioactive materials on the dentin surface whitened. Material and Methods: Three bovine teeth were shaped into three dentin wafers. Each wafer was then sectioned, into six dentin slices. One slice from each tooth was distributed into one of 6 groups: $1 . C G=$ control group (distilled water); 2.WT = whitening treatment; 3.WT + MI Paste Plus, applied once a day; 4.WT + Relief ACP30, applied once a day for 30 mintes; 5.WT + Relief ACP60, applied once a day for 60 minutes; 6 .WT + Biosilicate ${ }^{\circledR}$, applied once a week. All groups were treated over 14 days. Results: CG presented all dentinal tubules occluded by smear layer; WT group was observed all dentinal tubules opened. In the groups 3, 4 and 6, tubules were occluded. Group 5, dentinal tubules were completely occluded by mineral deposits. Conclusion: The use of bioactive materials immediately after whitening treatment can reduce or even avoid the demineralization effect of whitening and avoid exposing dentinal tubules.
\end{abstract}

Keywords: dentin, dental whitening, remineralization

\section{Introduction}

Dentin hypersensitivity is considered to be partly due to the presence of dentinal tubules at the exposed dentin surface where the tubules are wider and more numerous than in nonsensitive areas ${ }^{1}$. The hydrodynamic theory assumes that a stimulus applied on the dentin surface causes movement of tubular fluid, which activates mechanoreceptor nerves, eliciting pain ${ }^{2}$. According to this theory, if the functional radius of opened dentinal tubules decreases, then the permeability is also decreased, reducing dentin sensitivity ${ }^{3}$.

Whitening gels can cause demineralization when in contact with dentin, for example in areas of gingival recession and non-carious lesions, and lead to unwanted side effects, such as the opening of the dentinal tubules ${ }^{4}$. Numerous research studies ${ }^{4-8}$ show that whitening agents can lead to alterations in the dental structure, perhaps due to the low $\mathrm{pH}$ of the gels and the presence of chelating agents ${ }^{5}$.

The resultant dental sensitivity can be a nuisance to most patients, while the prevention and treatment of the sensitivity is a challenge to most dentists ${ }^{6}$. The concern over the sensitivity brought by the whitening treatments has led the dental industry to develop whitening gels enhanced with desensitizers such as potassium nitrate and fluorides ${ }^{7,8}$. Nevertheless, these substances do not solve the issue completely, and do not reduce the demineralization process ${ }^{6}$.

Recently, the use of bioactive materials ACP (Amorphous Calcium Phosphate), CCP-ACP (Casein Phosphopeptite and Amorphous Calcium Phosphate), bioglass and bio-glass ceramics as desensitizers and remineralization agents have been used, but there is limited research on this area ${ }^{9-13}$. The main goal of these materials is to promote remineralization of the dental structures by the formation of a new layer of amorphous calcium phosphate on the surface where the product is applied. Latter on, the reaction with hydroxyl ions, carbonate and fluoride, which are available in the oral cavity, initiates the crystallization of a new surface layer into apatite ${ }^{14}$. This remineralization process seems to be much more effective than potassium nitrate or fluoride alone $e^{15,16}$, because it does not only act to relieve pain but prevents its onset.

This new therapy seems to be a viable alternative as the use of bio-active substances have been proven to be effective in preventing cavities and can be found in a wide variety of toothpastes, desensitizers, composites, sealants and chewing gum $^{17,18}$.

Respected authors ${ }^{19,20}$ use microscope images in high resolution to study the demineralization and remineralization phenomenon, both in dentin and enamel. The observation of structural and ultra-structural changes can enhance the understanding of the modifications caused by the use of whitening gels, therefore the use of high resolution and higher magnification images is recommended.

Perhaps the combined use of whitening gel and bio-active materials can contribute to less demineralization on the dental structures during the whitening treatment and consequently to reduced sensitivity during and after treatment. Nevertheless, there is little information in the literature regarding the use of these materials combined with whitening agents. Therefore, the main purpose of this study is to investigate the structure effects of 3 bio-active materials on whitened dentin using FEG-SEM (Field Emission Gum Scanning Electron Microscopy) images. The evaluation criteria used was the amount of dentinal tubules occluded or not. 


\section{Method}

\subsection{The dentin specimens were morphologicaly analyzed using a FEG-SEM.}

Samples: 3 bovine teeth were cleaned with ultrasound, pumice stone and water. All samples were stored in distilled water at $37{ }^{\circ} \mathrm{C}$.

Sample preparation: The incisal and cervical third of the crown portion of three bovine incisive were removed. Each tooth was then sectioned into six slices and divided into 6 groups. The samples were embedded in self-curing acrylic resin, serially gritted and polished using a polishing device (Knuth Rotor, Struers, Denmark) with aluminum oxide abrasive papers $(600 ; 800 ; 1,200 ; 1,500 ; 2,000$; 2,500 and 4,000 grit). The slices were ultrasonically cleansed in distilled water for 20 minutes to remove polishing residues. Then, were stored in distilled water at $37{ }^{\circ} \mathrm{C}$ for 24 hours. For each tooth, a slice was obtained for each of the treatment groups. This methodology allowed for standardization in relation to quantity, size and orientation of the dentinal tubules, facilitating the posterior morphologic comparison of the groups.

Materials used: The various products (Table 1) were applied to the surface of the samples according to the different groups.

Composition of the 3 bioactive materials used in this study: MI Paste Plus: $2 \%$ casein phosphopeptides (CPP)-amorphous calcium phosphate (ACP).

Relief ACP: $5 \%$ potassium nitrate; $0,22 \%$ sodium fluoride and $0,75 \%$ amorphous calcium phosphate (ACP).

Biosilicate $^{\circledR}:>99.5 \%$ crystalline glass-ceramic powder of the $\mathrm{P}_{2} \mathrm{O}_{5}-\mathrm{Na}_{2} \mathrm{O}-\mathrm{CaO}-\mathrm{SiO}_{2}$ system having a particle size distribution between 0.1 and $10 \mu \mathrm{m}$.

$\mathrm{pH}$ of the whitening gels: Before applying the whitening gels onto the samples the $\mathrm{pH}$ of the gels was measured using a digital $\mathrm{pH}$ measuring device (DIGIMED, model DM-20), which was calibrated with standard solutions with a $\mathrm{pH}=7$ and $\mathrm{pH}=4$.

Product application: The control group was stored in distilled water $\left(37^{\circ} \mathrm{C}\right)$. In the other groups was applied a $16 \%$ carbamide peroxide whitening gel (Perfect Whiteness-FGM) for 8 hours daily. After each application of whitening gel specimens were washed with distilled water.

In the groups WT + remineralizing products, the specimens were treated daily with the whitening gel for 8 hours, washed and then the remineralizing product was applied, according with the time application present in the Table 1. After this application period, the specimens were washed to be stored until the next day.

All products were applied during 14 consecutive days, except for Biosilicate ${ }^{\circledR}$ - Vitrovita, which was applied once a week.
The application of all products studied followed manufacturer's instructions regarding technique and time of contact, except for the group WT + Relief ACP 60, where the product was applied for 60 minutes, twice as long as manufacturer's instructions (Table 1).

All specimens were stored in distilled water at $37^{\circ} \mathrm{C}$. When treatment was completed at day 14 , samples were fixed in a glutaraldehyde solution, dehydrated in ethanol solutions and hexametildisilazane. After platinum coating, the dentinal surfaces were analyzed using FEG-SEM.

Ultra-structural analyzes: 18 specimens were divided into 6 groups (Figure 1). A FEG (JEOL JSM-7600F, Japan) was used to obtain five (5) representative images at magnification of 20,000 and $50,000 x$ from each specimen. All images were randomly presented to 3 calibrated examiners for evaluation of structural changes in the tubular dentin. All examiners used the same scoring system of $0-4$, in ascending order, from the best to worst situation. If dentinal tubules were completely occluded, score 0 was assigned to the specimen. Score 1 was given to specimens exhibiting $75 \%$ of the dentinal tubules occluded; score 2 for $50 \%$ and score 3 for $25 \%$ of the dentinal tubules occluded. If dentinal tubules were not occluded, score 4 was given.

Statistical analysis was performed using the Kruskal-Wallis test at a significance level of $95 \%$. The Kendall coefficient of concordance was used to measure the agreement between examiners.

\section{Results}

The $\mathrm{pH}$ of the whitening gel used in this study (Whiteness Perfect - FGM) was fond to be slightly acidic, at $\mathrm{pH}$ 5.9. Figure 1 shows that the untreated control group showed intact dentinal tubules, as expected (Figure 2a), the whitening treatment only group (WT) exhibit mostly open dentinal tubules (Figure 2b). For treatment groups WT + MI Paste Plus, WT + Relief ACP 30 e WT + Biosilicate ${ }^{\circledR}$, many of the dentinal tubes were obliterated (Figures $2 \mathrm{c}, \mathrm{d}$ and $\mathrm{f}$ respectively). For the group WT + Relief ACP 60 the dentinal tubules were completely obliterated (Figure 2e) and similar to untreated, intact dentin controls.

Table 2 presents the evaluators' scores of the changes observed in the specimens. WT group (whitening treatment only) was statistically different from all treated groups and untreated control. The Kruskal-Wallis test did not demonstrate statistically significant differences among untreated control group and any of the groups treated with the four different bioactive materials.

\section{Discussion}

Opening of the dentinal tubules is a problem that may occur when using a whitening gel, which has the potential to cause demineralization. If the gel is in contact with areas of exposed dentin, such as gingival recession and non-carious lesions ${ }^{21}$, the dentinal

Table 1. Materials used in the study, manufacturer, basic composition, and treatment protocol

\begin{tabular}{|c|c|c|c|c|c|c|c|}
\hline Groups & $\begin{array}{l}\text { Whitening } \\
\text { treatment }\end{array}$ & $\begin{array}{l}\text { Whitening product/ } \\
\text { manufacturer }\end{array}$ & $\begin{array}{c}\text { Remineralizing } \\
\text { treatment }\end{array}$ & $\begin{array}{l}\text { Remineralizing product/ } \\
\text { manufacturer }\end{array}$ & Basic-composition & $\begin{array}{l}\text { Application } \\
\text { time per day }\end{array}$ & $\begin{array}{l}\text { Total number } \\
\text { of applications }\end{array}$ \\
\hline $\begin{array}{l}\text { CG (Control } \\
\text { Group) }\end{array}$ & no & - & no & - & - & - & - \\
\hline $\begin{array}{l}\text { WT (Whitening } \\
\text { Treatment) }\end{array}$ & yes & $\begin{array}{l}\text { Whiteness Perfect / } \\
\text { FGM, Brazil }\end{array}$ & no & - & $\begin{array}{l}\text { Carbamide Peroxide } 16 \%+ \\
\text { Potassium Nitrate + Fluoride }\end{array}$ & 8 hours & 14 \\
\hline $\begin{array}{l}\text { WT + MI } \\
\text { Paste Plus }\end{array}$ & yes & $\begin{array}{c}\text { Whiteness Perfect / } \\
\text { FGM, Brazil }\end{array}$ & yes & MI Paste / GC, Japan & CPP-ACP + Fluoride & 5 minutes & 14 \\
\hline $\begin{array}{l}\text { WT + Relief } \\
\text { ACP } 30\end{array}$ & yes & $\begin{array}{l}\text { Whiteness Perfect / } \\
\text { FGM, Brazil }\end{array}$ & yes & $\begin{array}{l}\text { Relief ACP / Discus } \\
\text { Dental, USA }\end{array}$ & $\begin{array}{c}\text { Potassium nitrate + } \\
\text { Fluoride + ACP }\end{array}$ & 30 minutes & 14 \\
\hline $\begin{array}{l}\text { WT + Relief } \\
\text { ACP } 60\end{array}$ & yes & $\begin{array}{c}\text { Whiteness Perfect / } \\
\text { FGM, Brazil }\end{array}$ & yes & $\begin{array}{l}\text { Relief ACP / Discus } \\
\text { Dental, USA }\end{array}$ & $\begin{array}{c}\text { Potassium nitrate + } \\
\text { Fluoride + ACP }\end{array}$ & 60 minutes & 14 \\
\hline $\begin{array}{c}\text { WT + } \\
\text { Biosilicate }^{\circledR}\end{array}$ & yes & $\begin{array}{c}\text { Whiteness Perfect / } \\
\text { FGM, Brazil }\end{array}$ & yes & $\begin{array}{c}\text { Biosilicate }{ }^{\circledR} / \text { Vitrovita, } \\
\text { Brazil }\end{array}$ & $\begin{array}{l}\text { Glass-ceramic crystallized } \\
\text { glass } \mathrm{P}_{2} \mathrm{O}_{5}-\mathrm{Na}_{2} \mathrm{O}-\mathrm{CaO}-\mathrm{SiO}_{2}\end{array}$ & 5 minutes & 2 \\
\hline
\end{tabular}




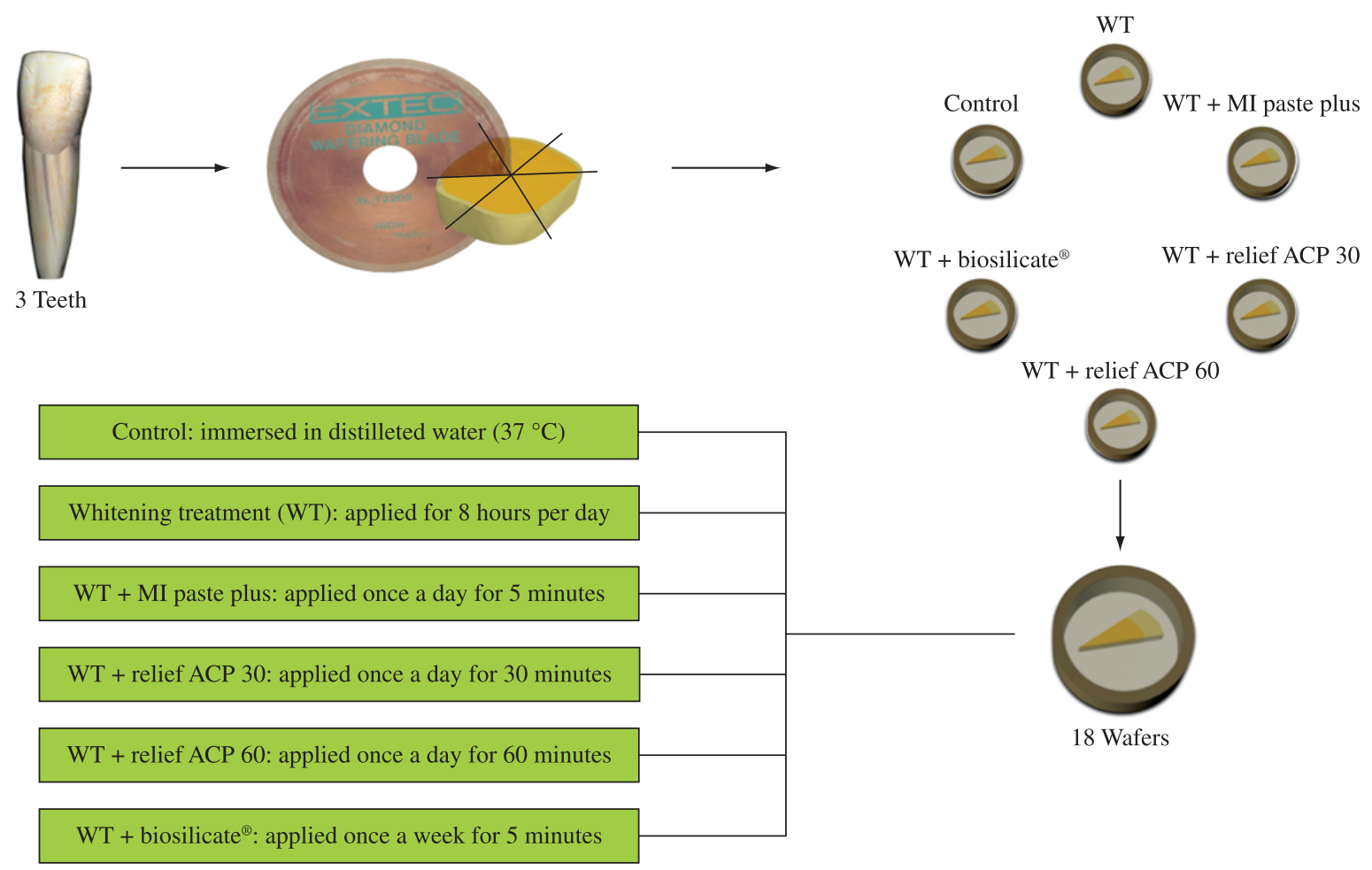

Figure 1. Study outline: preparing, cutting and separating into groups.

tubules will open, causing trans and post treatment sensitivity. Clinical studies have shown that approximately $55 \%$ of all patients evaluated after a whitening treatment with $10 \% \mathrm{CP}$ reported sensitivity. Of these patients, about two-thirds had gingival recession, flawed restorations or defects in the cement-enamel union ${ }^{22}$. Another study showed that patients with pre-existing sensitivity, as a consequence of root exposure, presented higher levels of trans- and post- whitening treatment sensitivity when compared to patients that did not present root exposure ${ }^{23}$

In the present study, the changes in the dental structure have been evaluated using scanning electronic microscope images.

There are several studies in the literature ${ }^{7,8,15,24-27}$ that show the influence of conventional bleaching agents (with potassium nitrate and fluoride) on tooth structure.

Hydrogen peroxide is also able to cause changes in the intertubular dentin and a significant decrease in microhardness values of dentin surface ${ }^{25}$. These changes resulted from the oxidative effect of peroxide that acts mainly on the organic components of dentin and the low $\mathrm{pH}$ of the $\mathrm{gel}^{6,25}$. However, as it is a recent development of the dental industry, the association of bioactive materials (ACP, $\mathrm{CCP}-\mathrm{ACP}$, bioglass and bio glass-ceramics) and bleaching agents lack on studies available in the literature.

Only two clinical studies ${ }^{28,29}$ were found that examined the effectiveness of the addition of amorphous calcium phosphate (ACP) to a whitening gel. These studies showed that the addition of ACP was a viable strategy to reduce trans- and post- bleaching sensitivity.

The variability of the results obtained in different research can be explained by the different methodology used, which varies according to the teeth used, $\mathrm{pH}$ and composition of the whitening gel studied, the solution used for sample storage and contact time of the whitening gels $^{(6)}$ and also because most studies do not consider the differences in the ultra-structure topography, using microscopic images of low magnification $^{30,31}$.
One of the most significant contributions of this study relies on the method used to obtain the specimens, where a sample was obtained from each tooth for all experimental groups. This facilitates the comparison between groups, as a significant degree of morphology variation can be found from one tooth to the next and that can influence the micro-structural analysis ${ }^{31}$. Most studies ${ }^{32-34}$ do not take this into consideration and use specimens for control group and experimental groups deriving from different teeth, furthermore SEM images obtained are frequently used only to illustrate the results. In this study, with the use of images in high magnification, it was possible to observe that the specimens in the control group presented obliterated dental tubules (Figure 2a). Nevertheless, the samples treated with the whitening gel (group WT) presented tubules that were wide open (Figure 2b), showing decalcification, which was confirmed by statistical analysis of the micrographs. This is most likely the effect of the acidic character and chelating agents in the gel. Some studies show that there is loss of calcium ${ }^{35,36}$ and phosphate ${ }^{25}$ on the surface of teeth structures in contact with whitening gels, which leads to dental demineralization. The peroxide can cause modifications in the dentin and significantly reduce its hardness. These changes are in general due to the low $\mathrm{pH}$ of the gels and the oxidation process of the peroxides, which mostly act on the organic components of dentin ${ }^{25}$.

The acidic whitening gel used here opened most dentinal tubules (Figure 2b), but they were closed on the specimens treated with MI Paste Plus, Relief ACP, and Biosilicate ${ }^{\circledR}$ (Figures 2c, 2d and 2f). This observation suggests that the combination of remineralizing products and whitening treatment can drastically reduce the number of opened dentin tubules. These remineralizing products may facilitate the deposition of $\mathrm{Ca}$ and $\mathrm{PO}_{4}$ ions lost during the whitening treatment, which precipitate in the form of amorphous calcium phosphate (ACP), forming an initial layer of new superficial amorphous calcium phosphates which eventually crystallize by the reaction with hydroxyl, carbonate and fluoride from the oral cavity. A recent clinical study 


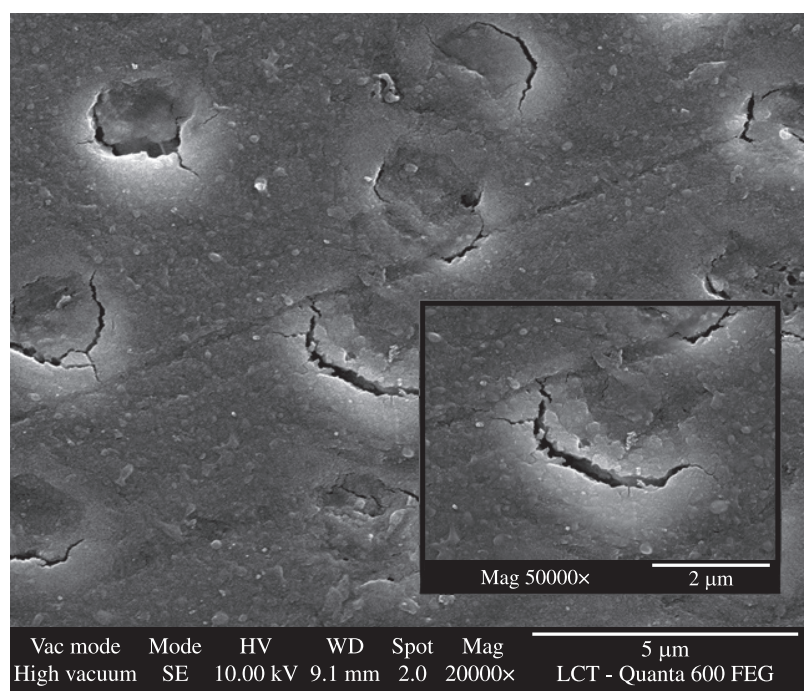

(a)

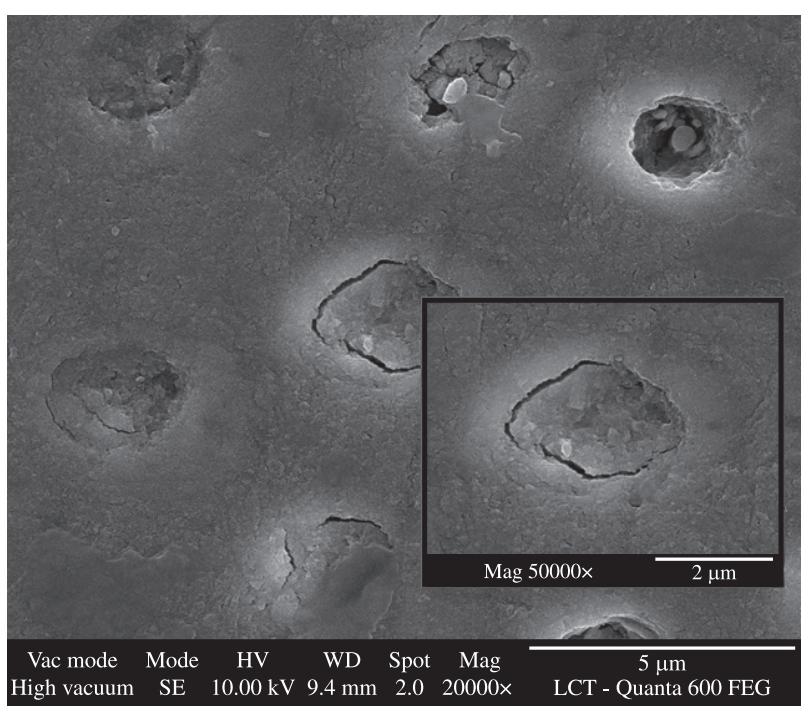

(c)

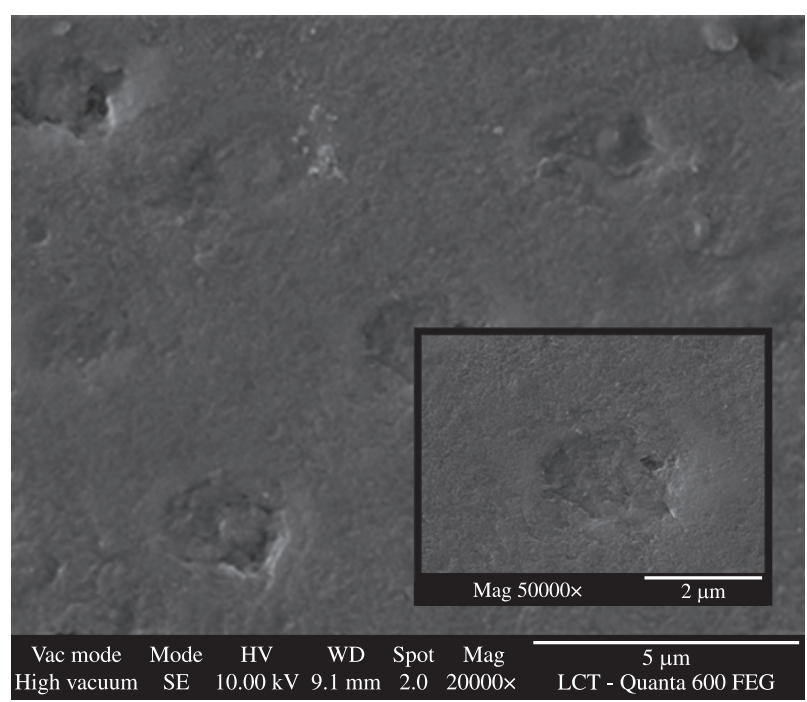

(e)

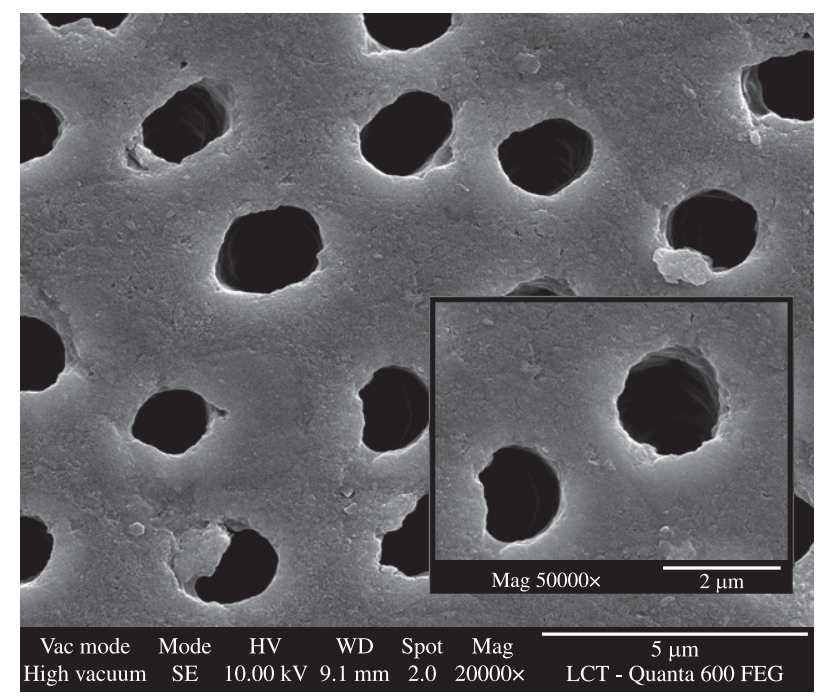

(b)

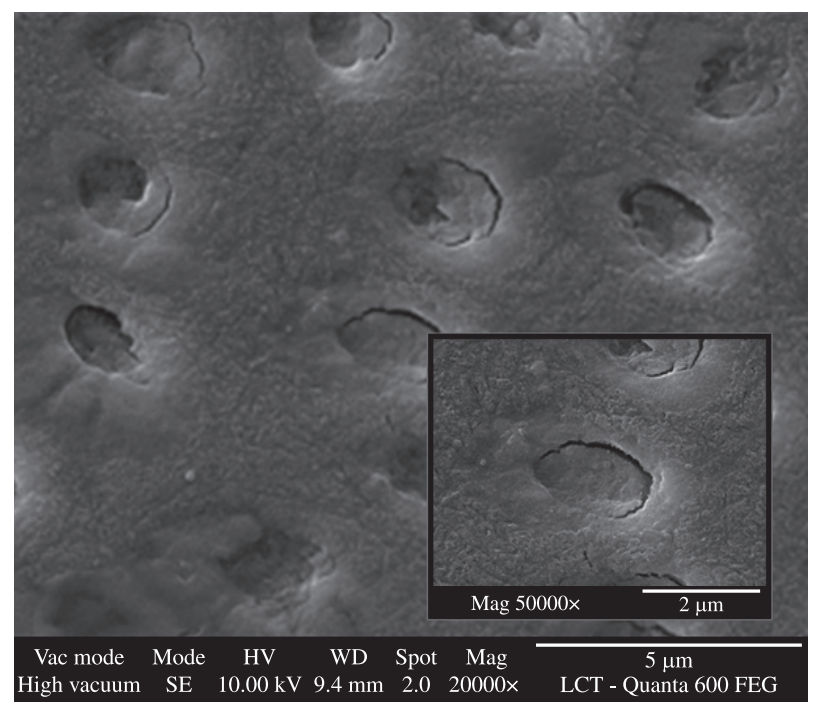

(d)

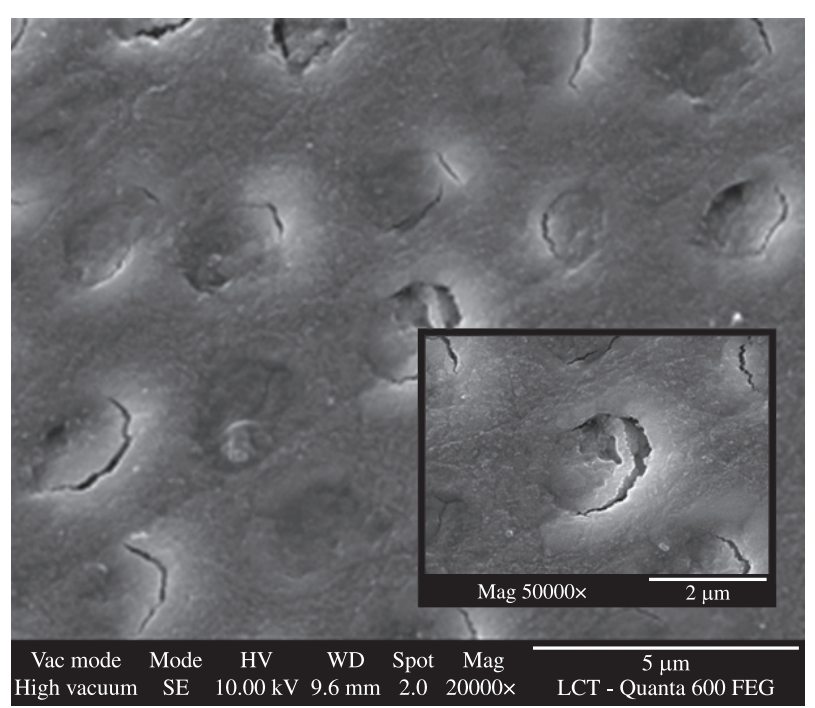

(f)

Figure 2. Representative FEG-SEM micrographs (original mag. $=20.000 \times$ ) of dentin tubular surface: a) Control - untreated dentin; b) dentin surface after whitening treatment (WT); c) after WT + MI Paste; d) after WT + Relief ACP 30 minutes; e) after WT + Relief ACP 60 minutes; f) after WT + Biosilicate ${ }^{\circledR}$ $($ Insets $=$ original mag. $=50.000 \times)$. 
Table 2. Score means and statistical data of changes found in the different groups.

\begin{tabular}{lc}
\hline \multicolumn{1}{c}{ Group } & Score mean \\
\hline WT (whitening treatment) & $3.7^{\mathrm{A}}$ \\
WT + MI Paste Plus & $0.3^{\mathrm{B}}$ \\
WT + ACP 30 minutes & $0.6^{\mathrm{B}}$ \\
WT + ACP 60 minutes & $0.0^{\mathrm{B}}$ \\
WT + Biosilicate & $1.0^{\mathrm{B}}$ \\
Control (without treatment) & $0.0^{\mathrm{B}}$ \\
\hline
\end{tabular}

Kruskal-Wallis test; means labeled with the same superscript letters were not statistically different $(\mathrm{p}<0.05)$.

reported a reduction on the trans- and post- treatment sensitivity with the use a whitening gel enhanced with $\mathrm{Ca}$ and $\mathrm{PO}_{4}^{29}$. This mineral deposition may be related to the reduction of sensitivity, but additional clinical evidence is needed.

In the specimens that were whitened and treated with Relief ACP for 60 minutes daily, with an application time twice as long as recommended by the manufacturer, the dentinal tubules were completely obliterated (Figure 2e). The longer application time may have positively influenced the obliteration of the tubules leading to a higher level of remineralization. However, the statistical analysis of micrographs revealed no statistically significant difference between this and the other groups bleached and treated with bioactive materials. This may be related to the use of non-parametric analysis and limited sample size.

Because of the sensitivity ${ }^{23,28}$, and the structural ${ }^{37-39}$ and chemical $^{36,40,41}$ changes caused by whitening agents, the supply of $\mathrm{Ca}$ and $\mathrm{PO}_{4}$ ions (through $\mathrm{ACP}$ technology) in conjunction with the whitening treatment may be a helpful approach to minimizing the loss of minerals, as well as the occurrence of porosity and erosion in the dental structure resulting from whitening treatments ${ }^{14,28}$. This combination is likely to reduce the trans- and post- treatment sensitivity by obliterating the dentinal tubules ${ }^{11}$.

Other factors that show the efficiency of bioactive materials on tooth structure could be further investigated, for example, precipitation depth and chemical analysis of the precipitate.

\section{Conclusion}

The use of bioactive materials, such as ACP and Biosilicate ${ }^{\circledR}$ glass-ceramic, together with whitening treatments can promote remineralization and close the dentinal tubules. Further investigation is needed to evaluate the role of these changes in reducing whitening-related dental sensitivity.

\section{Acknowledgements}

The authors recognize and thank Mr. Paulo Eduardo Ferreira Santos for the drawings in this article.

\section{References}

1. Pashley DH, Livingston MJ and Greenhill JD. Regional resistances to fluid flow in human dentine in vitro. Archives of Oral Biology. 1978; 23(9):807-810.

2. Brannstrom M. The hydrodynamic theory of dentinal pain: sensation in preparations, caries, and the dentinal crack syndrome. Journal of Endodontics. 1986; 12(10):453-457.

3. Greenhill JD and Pashley DH. The effects of desensitizing agents on the hydraulic conductance of human dentin in vitro. Journal of Dental Research. 1981; 60(3):686-698.
4. Pereira GDS. Considerações sobre sensibilidade pós-clareamento. CIOSP. 2002; 1:386-394.

5. Basting RT, Rodrigues Jr. AL and Serra MC. The effect of $10 \%$ carbamide peroxide, carbopol and/or glycerin on enamel and dentin microhardness. Operative Dentistry. 2005; 30(5):608-616.

6. Minoux M and Serfaty R. Vital tooth bleaching: biologic adverse effects: a review. Quintessence International Journal. 2008; 39(8):645-659.

7. Attin T. Susceptibility of enamel surfaces to demineralization after application of fluoridated carbamide peroxide gels. Caries Research. 2003; 37(2):29-39.

8. Attin T, Kielbassa AM, Schwanenberg M and Hellwig E. Effect of fluoride treatment on remineralization of bleached enamel. Journal Oral Rehabilitation. 1997; 24(4):282-286.

9. Poggio C, Lombardini M, Dagna A, Chiesa M and Bianchi S. Protective effect on enamel demineralization of a CPP-ACP paste: an AFM in vitro study. Journal of Dentistry. 2009; 37(12):949-954.

10. Rahiotis C and Vougiouklakis G. Effect of a CPP-ACP agent on the demineralization and remineralization of dentine in vitro. Journal of Dentistry. 2007; 35(8):695-698.

11. Tirapelli C. Avaliação da eficácia de um biomaterial e conhecidos agentes dessensibilizantes no tratamento da hipersensibilidade dentinária-estudo in vitro e in vivo. Ribeirão Preto: Faculdade de Odontologia de Ribeirão Preto; 2007.

12. Tung MS and Eichmiller FC. Amorphous calcium phosphates for tooth mineralization. Compendium of Continuing Education in Dentistry. 2004; 25(9):9-13.

13. Wang ZJ, Sa Y, Ma X, Wang YN and Jiang T. The preparation of nano-hydroxyapatite and preliminary observation on its effects on the occlusion of dentinal tubule. Zhonghua Kou Qiang Yi Xue Za Zhi. 2009; 44(5):297-300.

14. Geiger S, Matalon S, Blasbalg J, Tung M and Eichmiller FC. The clinical effect of amorphous calcium phosphate (ACP) on root surface hypersensitivity. Operative Dentistry. 2003; 28(5):496-500.

15. Tschoppe P, Neumann K, Mueller J and Kielbassa AM. Effect of fluoridated bleaching gels on the remineralization of predemineralized bovine enamel in vitro. Journal of Dentistry. 2009; 37(2):156-162.

16. Giannini M, Cavalli V and Paes Leme AF. Effect of carbamide peroxidebased bleaching agents containing fluoride or calcium on tensile strength of human enamel. Journal of Applied Oral Science. 2006; 11:82-87.

17. Esberard RR, Consolaro A, Esberard RM, Bonetti I and Esberard RR. Efeitos das técnicas e dos agentes clareadores externos na morfologia da junção amelocementária e nos tecidos dentários que a compõe. Revista Dental Press de Estética. 2004; 1(1):58-72.

18. Joiner A. The bleaching of teeth: a review of the literature. Journal of Dentistry. 2006; 34:412-419.

19. Fejerskov O and Kidd E. Características Clínicas e Histológicas da Cárie Dentária: a doença e seu tratamento clínico. São Paulo: Santos; 2005. p. 71-84.

20. Breschi L, Gobbi P, Mazzotti G, Ellis TH, Sacher E and Stangel I. Field emission in-lens SEM study of enamel and dentin. Journal of Biomedical Materials Research. 1999; 46(3):315-323.

21. Esberard R, Esberard RR, Esberard RM, Consolaro A and Pameijer CH. Effect of bleaching on the cemento-enamel junction. American Journal of Dentistry. 2007; 20(4):245-249.

22. Leonard Jr. RH, Haywood VB and Phillips C. Risk factors for developing tooth sensitivity and gingival irritation associated with nightguard vital bleaching. Quintessence International Journal. 1997; 28(8):527-534.

23. Jorgensen MG and Carroll WB. Incidence of tooth sensitivity after home whitening treatment. Journal of American Dental Association. 2002; 133(8):1076-1082.

24. Azer SS, Machado C, Sanchez E and Rashid R. Effect of home bleaching systems on enamel nanohardness and elastic modulus. Journal of Dentistry. 2009; 37(3):185-190.

25. Chng HK, Ramli H, Yap AUP and Lim CT. Effect of hydrogen peroxide on intertubular dentine. Journal of Dentistry. 2005; 33(5):363-369. 
26. Joiner A, Thakker $\mathrm{G}$ and Cooper Y. Evaluation of a $6 \%$ hydrogen peroxide tooth whitening gel on enamel and dentin microhardness in vitro. Journal of Dentistry. 2004; 32(1):27-34.

27. Maia E, Baratieri LN, Andrada MAC, Monteiro Jr. S and VIEIRA LCC. The influence of two home applied bleaching agents on enamel microhardness: an in situ study. Journal of Dentistry. 2008; 36(1):2-7.

28. Giniger M, MacDonald BS, Ziembra S and Felix H. The clinical performance of professionally dispensed bleaching gel with added amorphous calcium phosphate. JADA. 2005; 133:383-392.

29. Discus Dental International. Comparative study of original nitewhite vs new nitewhite acp: a 180-day study of tooth color \& three sensitivity measures. Rydalmere; 2004. 3 p.

30. Ben-Amar A, Liberman R, Gorfil C and Bernstein Y. Effect of mouthguard bleaching on the enamel surface. American Journal of Dentistry. 1995; 8(1):29-32.

31. Spaldin M, Taveira LAA and Assis GF. Scanning electron microscopy study of dental enamel surface exposed to $35 \%$ hydrogen peroxide: alone, with saliva, and with $10 \%$ Carbamide Peroxide. Journal of Esthetic and Restorative Dentistry. 2003; 15(3):154-164.

32. Bitter NC. A scanning electron microscopy study of the longterm effect of bleaching agents on the enamel surface in vivo. General Dentistry Journal. 1998; 46(1):84-88.

33. Josey AL, Meyers IA, Romaniuk K and Symons AL. The effect of a vital bleaching technique on enamel surface morphology and the bonding of composite resin to enamel. Journal of Oral Rehabilitation. 1996; 23(4):244-250
34. Zalkind M, Arwaz JR, Goldman A and Rotstein I. Surface morphology changes in human enamel, dentin and cementum following bleaching: a scanning electron microscopy study. Endodontics Dental Traumatology Journal. 1996; 12(2):82-88.

35. McCracken MS and Haywood VB. Effects of $10 \%$ carbamide proxide on the subsurface hardness of enamel. Quintessence. 1995; 26(1):21-24.

36. Rotstein I, Dankner E, Goldman A, Heling I, Stabholz A and Zalkind M. Histochemical analysis of dental hard tissues following bleaching. Journal of Endodontics. 1996; 22(1):23-25.

37. Basting RT, Rodrigues AL and Serra MC. Micromorphology and surface roughness of sound and demineralized enamel and dentin bleached with a $10 \%$ carbamide peroxide bleaching agent. American Journal of Dentistry. 2007; 20(2):97-102.

38. Romano JJF, Turssi CP, Rodrigues AL and Serra MC. Concentrationdependent effect of bleaching agents on micro hardness and roughness of enamel and dentin. American Journal of Dentistry. 2007; 20(1):31-40.

39. Schiavoni RJ, Turssi CP, Rodrigues AL, Serra MC, Pécora JD and Froner IC. Effect of bleaching agents on enamel permeability. American Jorunal of Dentistry. 2006; 19(5):313-316.

40. Cimilli $\mathrm{H}$ and Pamejer $\mathrm{CH}$. Effect of carbamide peroxide bleaching agents on the physical properties and chemical composition of enamel. Journal of American Dental Association. 2001; 14(2):63-66.

41. Potocnik I, Kosec L and Gaspersic D. Effect of $10 \%$ carbamide peroxide bleaching gel on enamel microhardness, microstructure, and mineral content. Journal of Endodontics. 2000; 26(4):203-206. 